\title{
Optimization of Cutting Parameters in Face Milling of Nodular Cast Iron for Minimum Surface Residual Stress Using the Taguchi Method
}

\author{
Yamin Zhu*, Kuanmin Mao, Xunxing Yu
}

School of Mechanical Science and Engineering, Huazhong University of Science and Technology, 1037 Luoyu Road, Hongshan District, Wuhan, 430074 Hubei, China.

* Corresponding author. Tel.: 13517226919; email: smedlut@hust.edu.cn Manuscript submitted May 18, 2018; accepted August 8, 2018.

doi: 10.17706/ijcee.2018.10.4.302-307

\begin{abstract}
Despite numerous studies focused on the residual stress induced from various machining parameters, the optimization of process parameters for the minimum residual stress machining of nodular cast iron has not been found in the current research. This paper aimed to optimize the milling parameters for low residual stress when nodular cast iron was machined. The experiments were performed with three control factors: cutting speed, feed rate and depth of cut in an $\mathrm{L}_{16}\left(4^{3}\right)$ orthogonal array. The X-ray diffraction (XRD) technique was used to measure the residual stresses in both directions. The results indicate that the cutting speed and feed rate but depth of cut play crucial roles in minimizing the residual stress.
\end{abstract}

Key words: Face milling, nodular cast iron, residual stress, Taguchi method, X-ray diffraction.

\section{Introduction}

Residual stress is an essential factor during machining process, as it predominantly impacts the final performance of the parts [1]. It is generally recognized that the compressive residual stress can promote but the tensile residual stress impair the fatigue life of the components. Sigwart and Fessenmeyer claimed that fatigue limit of turned 42CrMo4 steel specimens with high tensile residual stress had approximately $30 \%$ decreased through fatigue tests [2]. Recently, dimensional instability of the machined parts, under the relaxation of the residual stress after metal cutting, has also been an current issue. E. Brinksmeier et al. observed that maching-induced residual stress caused the dimensional deviations of bearing rings [3].

In fact, residual stress during the manufacturing operations is closely correlated with cutting parameters. Due to the complexity of material behaviour in machining process, experimental studies have still been a feasible solution to minimize the machining-induced residual stress in practice. Hence, the selection of machining parameters is critical for high precision product.

Although machining-induced residual stress has been extensively experimentally and numerically studied in the literature [4], [5], no publication has addressed the optimization of machining parameters in nodular cast iron for low residual stress. Thus, to lessen the influence of residual stress on manufactured parts, the selection of machining parameters and its effect on the residual stress must be investigated in the milling. This study aims to identify the optimal machining parameters (e.g. cutting speed, feed rate and depth of cut) for low residual stress when machining nodular cast iron. In this work, the $\mathrm{L}_{16}\left(4^{3}\right)$ orthogonal experiment were applied to find the optimal machining parameters based on the Taguchi method. 


\section{Experiment}

\subsection{Specimen Preparation}

The annealed samples were $50 \mathrm{~mm} \times 90 \mathrm{~mm} \times 90 \mathrm{~mm}$. Its chemical composition is summarized in Table 1.

Table 1. Chemical Composition of the Work Material

\begin{tabular}{llllllll}
\hline \hline element & $\mathrm{C}$ & $\mathrm{Si}$ & $\mathrm{Mn}$ & $\mathrm{P}$ & $\mathrm{S}$ & $\mathrm{Mg}$ & $\mathrm{Ce}$ \\
\hline content\% & 3.57 & 2.65 & 0.56 & 0.054 & 0.0125 & 0.056 & 0.011 \\
\hline \hline
\end{tabular}

A face-milling cutter $\phi 63 \mathrm{~mm}$ with 5 indexable cutter inserts was used. The cutter had a primary clearance angle of $11^{\circ}$ and a lead cutting edge angle of $90^{\circ}$. All cutting tests were performed under dry conditions. The experimental configuration used in this study is shown in Fig. 1.

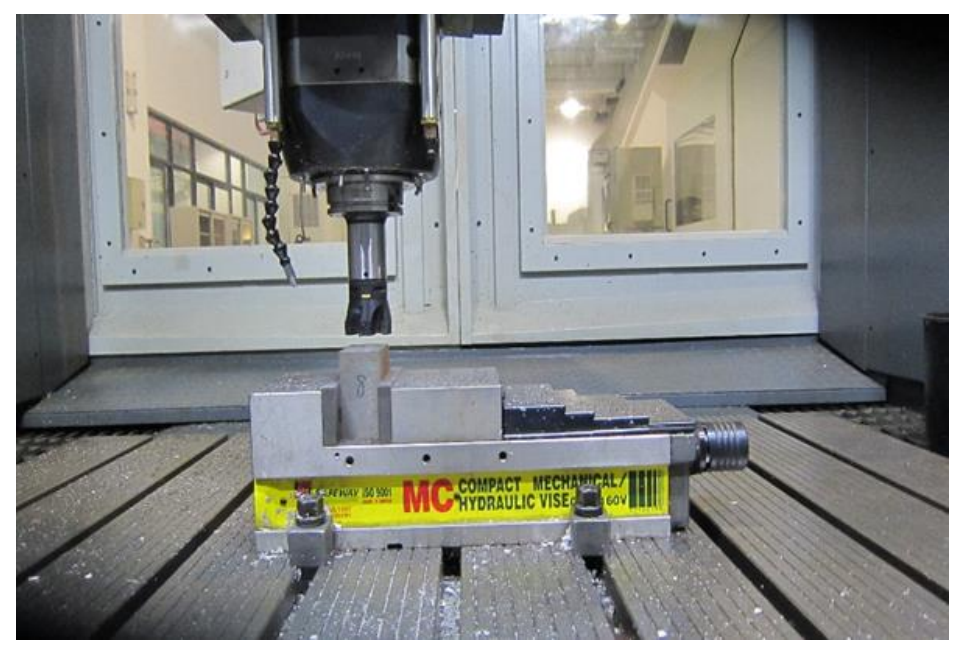

Fig. 1. Machining configuration.

\subsection{XRD Technique}

The X-ray diffraction (XRD) method, one of non-destructive techniques, is commonly applied to measure the residual stress [6]. In this experiment, $\mathrm{X}$-ray radiation with a target of material $\mathrm{Cr} \mathrm{K} \alpha$ was selected.

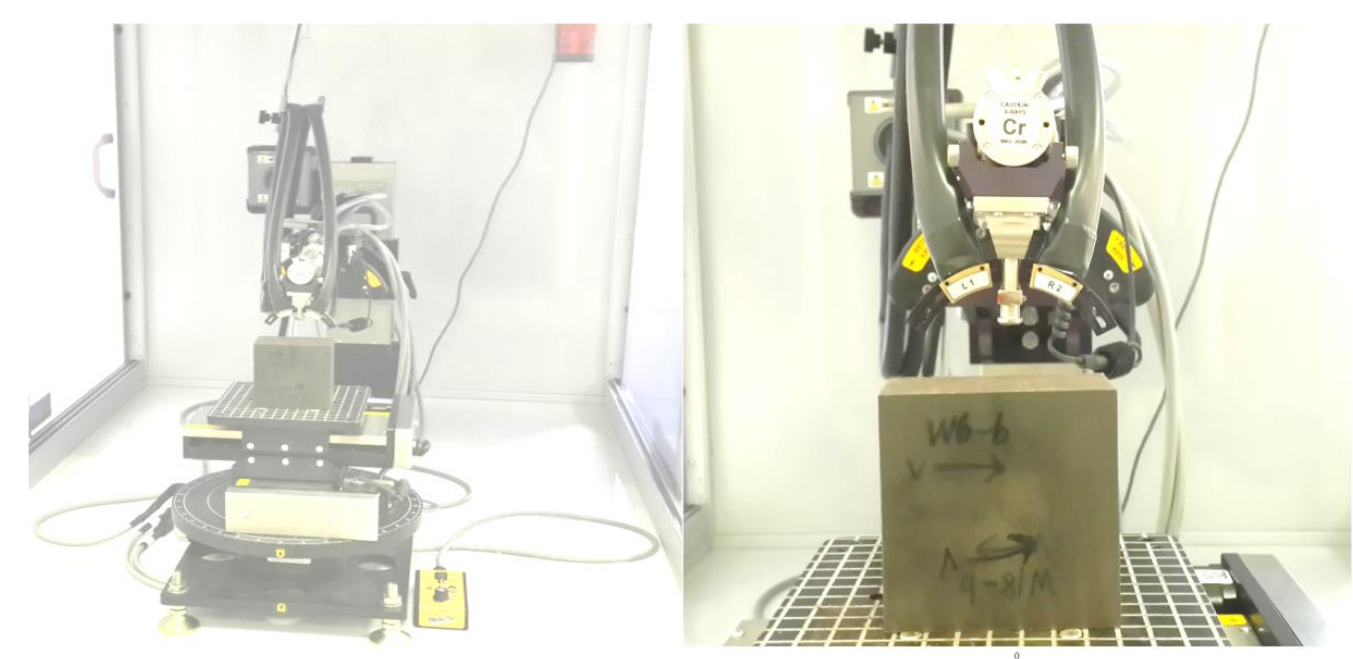

Fig. 2. XRD system to measure the machining-induced residual stress. 
A round collimator with a $1 \mathrm{~mm}$ hole was used to conduct the measurements. The diffraction angle $2 \theta$ $\left(156.41^{\circ}\right)$ was recommended for standardized parameters, respectively. The voltage of X-ray and the current was $20 \mathrm{Kv}$ and $4 \mathrm{~mA}$, respectively. The residual stress was analysed according to the standard $\sin ^{2} \psi$ method. Fig. 2 showed the residual stress measurement system.

\subsection{Taguchi's Method}

The Taguchi design method is a product of statistical and engineering techniques [7]. In this technique, an orthogonal array (OA) dramatically decreases the number of trials required by a large number of control factors and can effectively optimize the process parameters in the feasible parameter space [8]. In the present study, 'the smaller, the better' is used to minimize the machining-induced residual stress. Table 2 llustrated the selected control factors with each level and their physical meaning. The order of the experiment was randomized and the tests were repeated three times.

Table 2. Selected Control Factors and Levels in the Experiment

\begin{tabular}{llllll}
\hline \hline Control factor & Machining parameters & Level 1 & Level 2 & Level 3 & Level 4 \\
\hline A & cutting speed(m/min) & 90 & 110 & 130 & 150 \\
\hline B & feed rate $(\mathrm{mm} / \mathrm{z})$ & 0.1 & 0.18 & 0.26 & 0.34 \\
\hline $\mathrm{C}$ & depth of cut $(\mathrm{mm})$ & 0.1 & 0.2 & 0.3 & 0.4 \\
\hline \hline
\end{tabular}

In this method, the measured residual stress in the feed direction and cutting direction were placed in the individual column. The calculated means for the residual stress in both directions were shown in Table 3. Where $S_{11}$ was the average stress along the feed direction. $S_{22}$ denoted that in the cutting direction.

Table 3. $\mathrm{L}_{16}\left(4^{3}\right)$ Orthogonal Array for Residual Stress in Both Directions

\begin{tabular}{llllll}
\hline \hline & Control factor & & & \multicolumn{2}{l}{ Residual stress(MPa) } \\
\cline { 2 - 6 } No & A & B & C & $S_{11}$ & $S_{22}$ \\
\hline 1 & 1 & 1 & 1 & 100.80 & 91.83 \\
2 & 1 & 2 & 2 & 128.10 & 105.57 \\
3 & 1 & 3 & 3 & 205.10 & 175.30 \\
4 & 1 & 4 & 4 & 305.03 & 207.77 \\
5 & 2 & 1 & 2 & 172.10 & 106.83 \\
6 & 2 & 2 & 1 & 283.73 & 181.33 \\
7 & 2 & 3 & 4 & 214.50 & 205.07 \\
8 & 2 & 4 & 3 & 237.50 & 269.07 \\
9 & 3 & 1 & 3 & 32.53 & 94.33 \\
10 & 3 & 2 & 4 & 331.20 & 362.27 \\
11 & 3 & 3 & 1 & 383.93 & 324.90 \\
12 & 3 & 4 & 2 & 201.20 & 303.37 \\
13 & 4 & 1 & 4 & 314.20 & 215.43 \\
14 & 4 & 2 & 3 & 447.00 & 368.67 \\
15 & 4 & 3 & 2 & 431.80 & 369.40 \\
16 & 4 & 4 & 1 & & 416.20 \\
\hline \hline
\end{tabular}

Fig. 3 showed that the residual stress in the feed direction sharply increased as the cutting speed soared. The feed rate variation on the residual stress illustrated that the residual stress also increased with the rising feed rate, but there was no substanntial change in residual stress versus the depth of cut. Therefore, the selected factor levels for low residual stress in the feed direction were $A_{1}, B_{1}$, and $C_{3}$.

Similarly, there was an identical trend in the cutting direction (Fig. 4), and the factor levels were accordingly $A_{1}, B_{1}$, and $C_{2}$ for minimal residual stress in the cutting direction. The temperature rose with cutting speed and feed rate.It is because that an rising cutting speed can lead to a moderate reduction in the 
cutting force and feed force but cutting force and feed force soared as feed rate increased in this work [9]-[11].

In view of 'the smaller, the better', it was the best for a given level of each factor when the mean residual stress was reached. Because the depth of cut had a minor range, its effect was negligible. The cutting speed and the the feed rate had great effect on the residual stress. Thus, to realize the minimal residual stress, the optimal level was $A_{1}, B_{1}$.

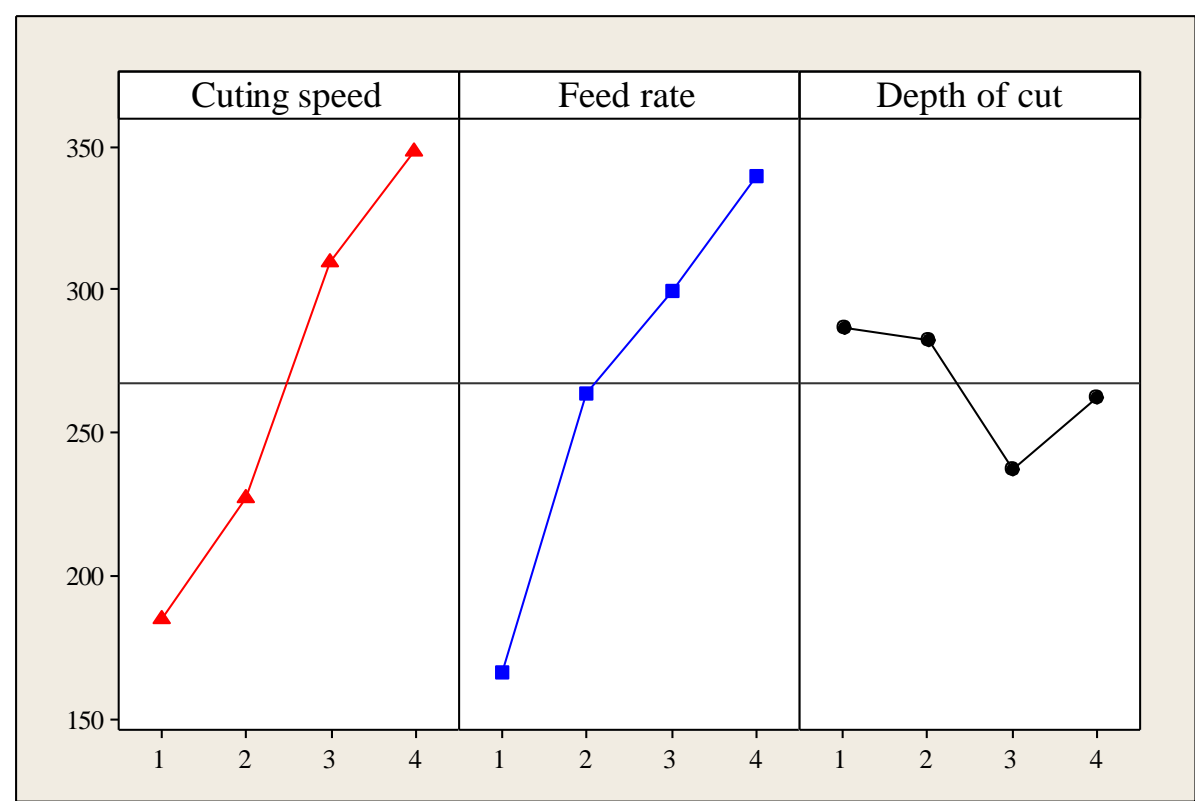

Fig. 3. Mean plot for the residual stress along the feed direction.

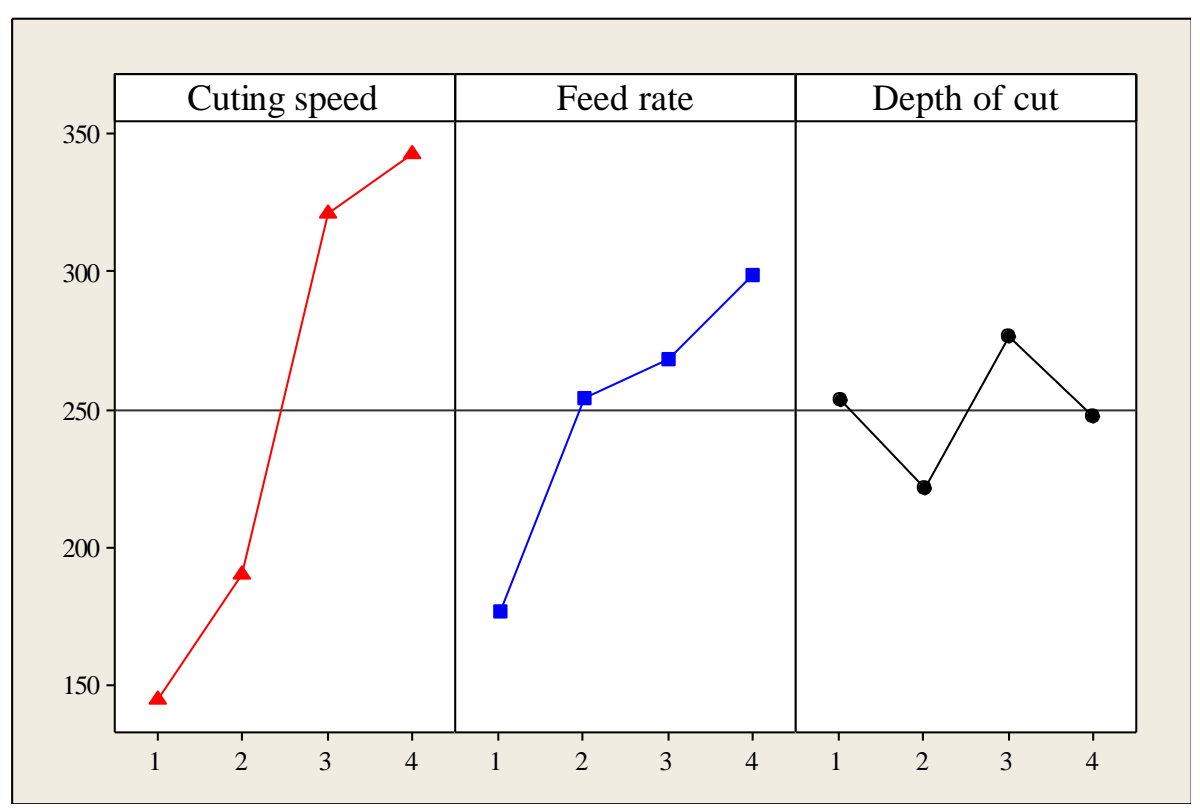

Fig. 4. Mean plot for the residual stress along the feed direction.

\section{Conclusion}

The current work focused on investigating the effect of the process parameters on the surface residual stress in machining nodular cast iron using the Taguchi method. Three machining parameters (cutting 
speed, feed rate and depth of cut) were taken as the control factors to carry out the experiment. The optimal machining parameters were estimated based on the main effect plots of means.

\section{Acknowledgment}

This work has been funded by the National High Technology Research and Development Program of China (No. 2012AA040702 and No. 2012AA040703).

\section{References}

[1] Brinksmeier, E., Cammett, J. T., König, W., Leskovar, P., Peters, J., \& Tönshoff, H. K. (1982). Residual stresses - Measurement and causes in machining processes. CIRP Annals - Manufacturing Technology, 31(2), 491-510.

[2] El-Axir, M. H. (2002). A method of modeling residual stress distribution in turning for different materials. International Journal of Machine Tools and Manufacture, 42(9), 1055-1063.

[3] Brinksmeier, E., Sölter, J., \& Grote, C. (2007). Distortion engineering - Identification of causes for dimensional and form deviations of bearing rings. CIRP Annals - Manufacturing Technology, 56(1), 109-112.

[4] Ulutan, D., \& Ozel, T. (2011). Machining induced surface integrity in titanium and nickel alloys: A review. International Journal of Machine Tools and Manufacture, 51(3), 250-280.

[5] Özel, T., \& Ulutan, D. (2012). Prediction of machining induced residual stresses in turning of titanium and nickel based alloys with experiments and finite element simulations. CIRP Annals - Manufacturing Technology, 61(1), 547-550.

[6] Wither, P. J. (2001). Residual stress part 1-Measurement techniques. Materials Science and Technolog, $17,355-365$.

[7] Indrajit, M. P. K. R. (2006). A review of optimization techniques in metal cutting processes. Computers \& Industrial Engineering, 50(1-2), 15-34.

[8] Masmiati, N., \& Sarhan, A. A. D. (2015). Optimizing cutting parameters in inclined end milling for minimum surface residual stress - Taguchi approach. Measurement, 60, 267-275.

[9] Grzesik, W., Rech, J., Żak, K., \& Claudin, C. (2009). Machining performance of pearlitic-ferritic nodular cast iron with coated carbide and silicon nitride ceramic tools. International Journal of Machine Tools and Manufacture, 49(2), 125-133.

[10] Grzesik, W., Kiszka, P., Kowalczyk, D., Rech, J., \& Claudin, C. (2012). Machining of nodular cast iron (PF-NCI) using CBN tools. Procedia CIRP, 1, 483-487.

[11] Yigit, R., Celik, E., Findik, F., \& Koksal, S. (2008). Tool life performance of multilayer hard coatings produced by HTCVD for machining of nodular cast iron. International Journal of Refractory Metals and Hard Materials, 26(6), 514-524.

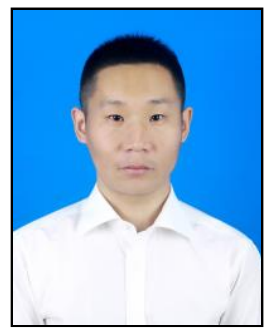

Yamin Zhu is a PH.D. candidate in the Department of Mechanical Design in Huazhong University of Science and Technology, Wuhan, 430074, PR China. He focuses on mechanics, statistical analysis, design and measurement of residual stress. 
Kuanmin Mao is a doctor of mechanical engineering. He is also a professor and a research fellow in State Key Laboratory of Digital Manufacturing Equipment and Technology in Huazhong University of Science and Technology, Wuhan, 430074, PR China. He is the deputy director of the Department of Mechanical Design.

His research interests include residual stress, structural dynamics, and mechanical design. He has presided over a variety of national program on key basic research of project ( 973 projects) and national high-tech R\&D program of China ( 863 programs), and published 48 papers and obtained 10 patents.

Xunxing Yu is a PH.D. candidate in the Department of Mechanical Design in Huazhong University of Science and Technology, Wuhan, 430074, PR China. He focuses on structural dynamics, design and measurement of rotors. 